\title{
Effects of evolocumab in individuals with type 2 diabetes with and without atherogenic dyslipidemia: An analysis from BANTING and BERSON
}

\author{
Alberto J. Lorenzatti ${ }^{*} \mathbb{C}$, Maria Laura Monsalvo², J. Antonio G. López ${ }^{2}$, Huei Wang ${ }^{3}$ and Robert S. Rosenson ${ }^{4}$
}

\begin{abstract}
Background: Atherogenic dyslipidemia (AD), characterized by increased concentrations of apolipoprotein B (ApoB)containing particles, is often present in individuals with type 2 diabetes mellitus (T2DM). Non-high-density lipoprotein cholesterol (non-HDL-C), cholesterol transported by apolipoprotein B (ApoB)-containing particles), and total apoB are considered secondary goals of lipid-lowering therapy to guide treatment of residual cardiovascular risk. The BANTING and BERSON studies demonstrated that evolocumab added to statin therapy reduced atherogenic lipid and lipoproteins concentrations in patients with T2DM.

Methods: This post-hoc analysis combined data from two randomized, placebo-controlled trials, BANTING and BERSON, to investigate the effect of evolocumab (140 mg every two weeks [Q2W] or $420 \mathrm{mg}$ monthly [QM]) on atherogenic lipid (LDL-C, non-HDL-C, VLDL-C, remnant cholesterol) and lipoproteins (ApoB, lipoprotein(a) (Lp[a])), and achievement of 2019 European Society of Cardiology/European Atherosclerosis Society lipid treatment goals in individuals with and without AD.
\end{abstract}

Results: In individuals with high TGs with $(n=389)$ and without $(n=196)$ AD receiving background statin therapy, evolocumab, compared with placebo, substantially reduced the cholesterol levels from all ApoB atherogenic lipoproteins (least squares (LS) mean LDL-C by $66.7 \%$ to $74.3 \%$, non-HDL-C by $53.4 \%$ to $65.8 \%$, median remnant cholesterol by $28.9 \%$ to $34.2 \%$, VLDL-C by $16.1 \%$ to $19.6 \%$ ) and median TGs levels (by $17.5 \%$ to $19.6 \%$ ) at the mean of weeks 10 and 12. LS mean ApoB was significantly reduced by $41.5 \%$ to $56.6 \%$ at week 12 . Results were consistent in diabetic individuals with normal TGs ( $n=519)$. Evolocumab was also associated with a significant reduction in median Lp(a) by $35.0 \%$ to $53.9 \%$ at the mean of weeks 10 and 12 . A majority (74.7\% to $79.8 \%$ ) of evolocumab-treated individuals achieved the goal of both an $\mathrm{LDL}-\mathrm{C}<1.4 \mathrm{mmol} / \mathrm{L}$ and an $\mathrm{LDL}-\mathrm{C}$ reduction of at least $50 \%,>75 \%$ achieved non-HDL-C $<2.2 \mathrm{mmol} / \mathrm{L}$ at the mean of weeks 10 and 12, and $>67 \%$ achieved $A p o B<65 \mathrm{mg} / \mathrm{dL}$ at week 12.

Conclusions: Evolocumab effectively reduced LDL-C, non-HDL-C, ApoB, Lp(a), and remnant cholesterol in individuals with T2DM with and without AD. Evolocumab Q2W or QM enabled most individuals at high/very-high cardiovascular disease risk to achieve their $L D L-C$, non-HDL-C, and ApoB recommended goals.

*Correspondence: alorenzatti@damic.com.ar; alberto.lorenzatti@gmail.com

${ }^{1}$ Clinical Research and Cardiology, Instituto Médico DAMIC/Fundación

Rusculleda, Córdoba, Argentina

Full list of author information is available at the end of the article

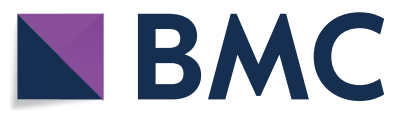

(c) The Author(s) 2021. This article is licensed under a Creative Commons Attribution 4.0 International License, which permits use, sharing, adaptation, distribution and reproduction in any medium or format, as long as you give appropriate credit to the original author(s) and the source, provide a link to the Creative Commons licence, and indicate if changes were made. The images or other third party material in this article are included in the article's Creative Commons licence, unless indicated otherwise in a credit line to the material. If material is not included in the article's Creative Commons licence and your intended use is not permitted by statutory regulation or exceeds the permitted use, you will need to obtain permission directly from the copyright holder. To view a copy of this licence, visit http://creativeco mmons.org/licenses/by/4.0/. The Creative Commons Public Domain Dedication waiver (http://creativecommons.org/publicdomain/ zero/1.0/) applies to the data made available in this article, unless otherwise stated in a credit line to the data. 
Keywords: Atherogenic dyslipidemia, Cardiovascular disease, Diabetes mellitus, Evolocumab, Lipid-lowering therapy, Lipoproteins, PCSK9 inhibition, Treatment goals

\section{Background}

The lipid profile of patients with atherogenic dyslipidemia $(\mathrm{AD})$ is generally characterized by high triglycerides (TGs), low high-density lipoprotein cholesterol (HDL-C), and mildly elevated or even normal low-density lipoprotein cholesterol (LDL-C) levels. The lipoprotein assessment in these patients reveals an increase in triglyceride-rich lipoproteins (TRL) (chylomicrons, verylow-density lipoprotein [VLDL]), accumulation of lipoprotein remnants (chylomicron remnants, small VLDL, and intermediate-density lipoprotein), and predominantly small, dense LDL particles $[1,2]$. The atherogenic nature is due to the increased number of apolipoprotein B (ApoB)-containing particles, also characterized by elevated non-HDL-C levels. Insulin resistance has been identified as the main factor for the development of $\mathrm{AD}$, which is often present in patients with insulin resistance phenotypically captured by obesity, metabolic syndrome, impaired glucose tolerance, and type 2 diabetes mellitus (T2DM) [3-5].

Epidemiological, clinical, and genetic studies have supported the AD's role as a causal factor for the development and progression of atherosclerotic cardiovascular disease (ASCVD) [6-12]. Many patients who attained their LDL-C goal with lipid-lowering therapies continue to experience cardiovascular events; the increase of other ApoB-containing lipoproteins likely contributes to the residual risk [13-18]. Thus, while LDL-C is the primary focus for dyslipidemia management and ASCVD prevention, it might not reflect the actual atherogenic burden in patients with $\mathrm{AD}$. In these patients, measuring both nonHDL-C and ApoB levels is recommended for ASCVD risk assessment [5]. Moreover, the 2019 European Society of Cardiology/European Atherosclerosis Society (ESC/ EAS) guidelines for the management of dyslipidemias have defined secondary goals for both non-HDL-C and ApoB to help guide lipid-lowering therapy adjustments after the achievement of an LDL-C goal [5].

Patients with type 2 diabetes mellitus (T2DM) are at exceptionally high risk of cardiovascular disease (CVD) morbidity and mortality; several society guidelines recommend an aggressive lipid management approach to reduce CVD risk [5, 19-21]. However, lipid levels in many patients with $\mathrm{T} 2 \mathrm{DM}$ receiving statin therapy remain above the recommended thresholds. A second therapy is needed to attain lipid treatment goals and further reduce the risk of cardiovascular events [22, 23]. In two double-blind, randomized, phase 3 studies of individuals with T2DM (BANTING, NCT02739984; BERSON, NCT02662569), evolocumab, a fully human monoclonal antibody that is a proprotein convertase subtilisin/kexin type 9 inhibitor (PCSK9i), significantly reduced LDL-C and other atherogenic lipid parameters when added on to statin therapy of at least moderate intensity [24, 25]. In two prespecified analyses of the FOURIER trial (NCT01764633), evolocumab also reduced the risk of major cardiovascular events (myocardial infarction, stroke, and coronary revascularization) with similar efficacy in patients with or without diabetes [26] and in patients with metabolic syndrome with or without diabetes [27] who were treated with a maximally tolerated dose of statin. Patients with established ASCVD also had a lower risk of developing complex coronary artery disease requiring revascularization (complex PCI or CABG) when evolocumab was added to statin therapy [28]. The benefits, which increased over time, extended to patients with diabetes in whom the risk was significantly reduced by $36 \%$.

In patients with T2DM at high or very high CVD risk who cannot attain their LDL-C goal with a maximally tolerated dose of statin in combination with ezetimibe, or in whom statins are not tolerated, the addition of a PCSK9i is recommended to achieve an $\mathrm{LDL}-\mathrm{C}<1.8 \mathrm{mmol} / \mathrm{L}$ (high-risk patients) or $<1.4 \mathrm{mmol} / \mathrm{L}$ (very high-risk patients) and reduce LDL-C by at least 50\% [19]. The lipid-lowering effect of evolocumab in the subgroup of T2DM patients with AD (high TGs and/or low HDLC) has not been previously reported. The objective of this post-hoc analysis was to investigate the effect of evolocumab on $\mathrm{ApoB}$, on cholesterol levels carried by ApoB-containing lipoproteins, on HDL-C, and on the achievement of 2019 ESC/EAS [5] lipid and lipoprotein treatment goals in patients with T2DM with and without AD.

\section{Methods}

This analysis included pooled data from two randomized, double-blind, 12-week studies of evolocumab vs placebo treatment, on background statin therapy of at least moderate intensity, in patients with T2DM and hypercholesterolemia or mixed dyslipidemia (BANTING [NCT02739984] [25] and BERSON [NCT02662569] [24]). For both studies, detailed methods, participant inclusion/exclusion criteria, and primary results have been previously published [24, 25, 29]. All procedures followed Good Clinical Practice, the protocols were 
approved by institutional review boards at participating sites, and all participants provided written informed consent at enrollment. An independent ethics committee or Ethics Review Board approved study protocols for all studies contributing data to this post-hoc analysis.

Participants in both studies were $\geq 18$ years of age, diagnosed with T2DM, had hemoglobin A1c $\leq 10 \%$, and had been on stable pharmacological therapy for diabetes for $\geq 6$ months. Fasting TGs were limited to $\leq 4.5 \mathrm{mmol} / \mathrm{L}$ in BERSON and $\leq 6.8 \mathrm{mmol} / \mathrm{L}$ in BANTING. Before randomization in BANTING [25], individuals without known clinical CVD were required to have a fasting LDL-C $\geq 2.59 \mathrm{mmol} / \mathrm{L}$ or non-HDL$\mathrm{C} \geq 3.39 \mathrm{mmol} / \mathrm{L}$ Individuals with known clinical CVD (defined as a history of myocardial infarction, stable or unstable angina, coronary or other arterial revascularization, stroke, transient ischemic attack, or peripheral arterial disease presumed to be of atherosclerotic origin) were required to have a fasting $\mathrm{LDL}-\mathrm{C} \geq 1.81 \mathrm{mmol} / \mathrm{L}$ or non-HDL-C $\geq 2.59 \mathrm{mmol} / \mathrm{L}$. In BERSON [24], individuals on statin therapy at screening were required to have an LDL-C $\geq 2.6 \mathrm{mmol} / \mathrm{L}$. Individuals who were not on statin therapy at screening were required to have an LDL-C $\geq 3.4 \mathrm{mmol} / \mathrm{L}$. Blood samples were obtained after fasting for a minimum of $9 \mathrm{~h}$.

In both studies, all participants were required to be on background statin therapy. In BANTING [25], individuals receiving maximally tolerated doses of statins of at least moderate intensity were randomized to receive evolocumab $420 \mathrm{mg}$ subcutaneous (SC) or placebo monthly (QM). In BERSON [24], participants who initiated atorvastatin $20 \mathrm{mg}$ at enrollment and then were randomized to receive evolocumab $140 \mathrm{mg}$ SC every 2 weeks (Q2W) or 420 mg SC QM or placebo Q2W or QM.

For the current analysis, individuals in the pooled full analysis sets of both studies (ie, participants who were randomized and received at least one dose of study drug [placebo or evolocumab]) were divided into three groups as follows:

(1) individuals with high TGs and normal HDL-C (i.e. without $\mathrm{AD}),(2)$ individuals with high TGs and low HDL-C (i.e. with AD), and (3) individuals with normal TGs and normal HDL-C levels. High TGs were defined as baseline TGs $\geq 1.69 \mathrm{mmol} / \mathrm{L}$, and low HDL-C was defined for male individuals as baseline $\mathrm{HDL}-\mathrm{C}<1.03 \mathrm{mmol} / \mathrm{L}$ and female individuals as baseline $\mathrm{HDL}-\mathrm{C}<1.29 \mathrm{mmol} / \mathrm{L}$ [30].

The pooled analysis endpoints of interest were percentage change from baseline and change from baseline in lipid values (LDL-C, non-HDL-C, ApoB, lipoprotein(a) [Lp(a)], VLDL-C, remnant cholesterol, TGs, and HDLC). In addition, we evaluated the percentage of individuals who attained lipid goals per the 2019 ESC/EAS guidelines for patients at high or very-high CVD risk [5]. The goals assessed were the following: $\geq 50 \%$ reduction in $\mathrm{LDL}-\mathrm{C}, \mathrm{LDL}-\mathrm{C}<1.4 \mathrm{mmol} / \mathrm{L}, \geq 50 \%$ reduction in $\mathrm{LDL}-\mathrm{C}$ and $\mathrm{LDL}-\mathrm{C}<1.4 \mathrm{mmol} / \mathrm{L}, \mathrm{LDL}-\mathrm{C}<1.0 \mathrm{mmol} / \mathrm{L}$, non-HDL-C $<2.6 \mathrm{mmol} / \mathrm{L}$, non-HDL-C $<2.2 \mathrm{mmol} / \mathrm{L}$, ApoB $<80 \mathrm{mg} / \mathrm{dL}$, and $\mathrm{ApoB}<65 \mathrm{mg} / \mathrm{dL}$. The correlation of ApoB100 with non-HDL-C, remnant cholesterol and TGs in patients treated with evolocumab $(\mathrm{Q} 2 \mathrm{~W}$ and QM combined) was also assessed.

Lipid and lipoprotein endpoints were measured at week 10 and week 12. The outcomes reported here are the means of weeks 10 and 12 except for total ApoB, which was not measured at week 10 in BERSON, so the results are reported at week 12 . ApoB100 was measured only in BERSON, per protocol, at weeks 10 and 12 . The final study drug dose was at week 8 in the BANTING study; for the BERSON study, it was at week 8 for QM participants and week 10 for Q2W participants. The maximum reduction of LDL-C occurs approximately 2 weeks after the dose for individuals receiving evolocumab $420 \mathrm{mg}$ QW [31]; therefore, the mean of weeks 10 and 12 incorporates time points that would likely represent maximum LDL-C reduction for some individuals, depending on their dose regimen, combined with a time point at which LDL-C levels are starting to return to baseline. The lipid endpoints at week 12 were also analyzed; the data are not reported here.

LDL-C was calculated using the Friedewald formula. When the calculated LDL-C was $<1.0 \mathrm{mmol} / \mathrm{L}$ or TGs were $>4.5 \mathrm{mmol} / \mathrm{L}$, calculated LDL-C was replaced with ultracentrifugation to inform LDL-C and VLDL-C from the same blood sample, if available. In both studies, total ApoB was measured by immunoturbidimetry and ELISA measured ApoB48, both at Medpace (Cincinnati, Ohio; Leuven, Belgium). For the BERSON study, because the protocol required $\mathrm{ApoB} 100$ and ApoB48 results separately, for this analysis, total $A p o B$ was the summation of ApoB100 and ApoB48 from the same blood sample. Remnant cholesterol was calculated as total cholesterol minus LDL-C and HDL-C from the same blood sample $[9,32]$.

\section{Statistical analysis}

Analysis of each endpoint comparing evolocumab vs placebo was conducted within each of the three groups (high TGs and normal HDL-C, high TGs and low HDL$\mathrm{C}$, normal TGs and normal HDL-C) and two dosing regimens (Q2W and QM) or both combined if sample size was small. For analyses of change and percentage change from baseline for endpoints that followed normal distributed data, treatment group differences (evolocumab minus placebo) were evaluated with a repeated measures linear effects model which included study, treatment 
group, scheduled visit, and the interaction of treatment group with scheduled visit as covariates. For analyses of change and percentage change from baseline for endpoints with skewed and non-normal distributed data, the median difference and 95\% CI are obtained from McKean-Schrader algorithm, and P-value is obtained from Quade test adjusting for baseline value. In addition, the relationship between changes in ApoB100 with changes in non-HDL-C, TGs, and remnant cholesterol within evolocumab was explored. The scatter plots, Pearson correlation coefficients, and associated $P$-values were generated for changes on the mean of weeks 10 and 12 from baseline in ApoB100 with changes on the mean of weeks 10 and 12 from baseline in non-HDL-C, TGs and remnant cholesterol for evolocumab for the overall and within each group. Spearman's rank correlation was used if the data was non-normal distributed. For the goal attainment analysis, treatment group differences were evaluated with Cochran-Mantel-Haenszel tests, stratified by study. Missing values were considered as non-attainment. Alpha levels were not adjusted for multiplicity. All analyses were performed using SAS version 9.4 (SAS Institute, Cary, NC, USA).

\section{Results}

The pooled BERSON and BANTING full analysis sets included 1402 participants (placebo, $\mathrm{n}=465$; evolocumab, $n=937$ ). A total of 1104 participants met the TGs and HDL-C criteria as follows: 196 participants (17.8\%) had high TGs and normal HDL-C; 389 participants (35.2\%) had both high TGs and low HDL-C, and 519 participants $(47.0 \%)$ had normal TGs and normal HDL-C.

\section{Baseline characteristics}

Baseline lipid profile, disease, and demographic variables are shown in Table 1 (detailed results by dose regimen are shown in, Additional file 1: Table S1). Baseline characteristics were generally well balanced between individuals allocated to placebo or evolocumab within each group. In all three groups, fasting serum glucose and duration of diabetes were higher in individuals allocated to evolocumab than to placebo. As expected, some baseline characteristics of the groups differed in some respects. Body mass index, waist circumference, any statin use, and high-intensity statin use were higher in the two groups with high TGs than in the group with normal TGs and normal HDL-C. LDL-C was higher in the group with high TGs without AD. Non-HDL-C, ApoB, VLDL-C, and remnant cholesterol were higher in the two groups of individuals with high TGs than in the group with normal TGs and normal HDL-C. Lp(a) was generally higher in the group with normal TGs and normal HDL-C. The percentage of Black or African American individuals was also higher in this group. Notably, individuals in the two groups with high TGs were more likely to be White and report Hispanic/ Latino ethnicity than were individuals with normal TGs.

\section{Lipid outcomes \\ Percentage change from baseline}

On top of background statin therapy, individuals treated with evolocumab, compared with placebo, had greater percentage change from baseline across all lipid parameters, with consistent results across dosing regimens and in individuals with and without high TGs (Figs. 1, 2 and Additional file 1: Table S2). At the mean of weeks 10 and 12, compared with placebo, evolocumab treatment reduced LDL-C by a least squares (LS) mean of $60.9 \%$ (95\% confidence interval [CI], 48.6, 73.2) with Q2W dosing and $74.3 \%$ (95\% CI 66.6, 81.9) with QM dosing in the group with high TGs and normal HDL-C, 69.8\% (95\% CI 61.6, 78.1) with Q2W dosing and 66.7\% (95\% CI 61.9, 71.5) with QM dosing in the group with high TGs and low HDL-C, and 72.4\% (95\% CI 63.2, 81.5) with Q2W dosing and 62.6\% (95\% CI 57.0, 68.3) with QM dosing in the group with normal TGs and normal HDL-C, all $P$-values $<0.0001$. Compared with placebo, evolocumab treatment reduced non-HDL-C by an LS mean of $46.9 \%$ (95\% CI 36.0, 57.9) with Q2W dosing and 65.8\% (95\% CI $58.8,72.8)$ with QM dosing in the group with high TGs and normal HDL-C, 59.2\% (95\% CI 50.2, 68.2) with Q2W dosing and 53.4\% (95\% CI 49.3, 57.6) with QM dosing in the group with high TGs and low HDL-C, and 63.9\% (95\% CI 56.1, 71.7) with Q2W dosing and 55.2\% (95\% CI 50.1, 60.3) with QM dosing in the group with normal TGs and normal HDL-C, all $P$-values $<0.0001$.

Significantly greater reductions with evolocumab treatment than placebo were also observed at week 12 for ApoB, and at the mean of weeks 10 and 12 for $\operatorname{Lp}(\mathrm{a})$, VLDL-C, remnant cholesterol, and TGs in individuals with and without high TGs (evolocumab Q2W and QM combined for VLDL-C, remnant cholesterol, and TGs; all $P$-values $<0.0001$ except for VLDL-C in the group with high TGs and normal HDL-C, $\mathrm{P}=0.0002$ ). For HDL$\mathrm{C}$, small, but significant, treatment differences favoring evolocumab were observed in patients with and without high TGs.

The analyses of percentage change from baseline with evolocumab treatment in LDL-C and non-HDL-C to the mean of weeks 10 and 12, and in total ApoB at week 12 were consistent between those receiving insulin (total $\mathrm{n}=352$ ) and those not receiving insulin therapy (total $\mathrm{n}=751$ ) across all 3 groups (data not shown). 
Table 1 Patient demographic and disease characteristics at baseline

\begin{tabular}{|c|c|c|c|c|c|c|}
\hline \multirow[t]{2}{*}{ Characteristic } & \multicolumn{2}{|c|}{ High TGs and normal HDL-C } & \multicolumn{2}{|c|}{ High TGs and low HDL-C } & \multicolumn{2}{|c|}{ Normal TGs and normal HDL-C } \\
\hline & Placebo $\mathrm{N}=64$ & $\begin{array}{l}\text { Evolocumab } \\
N=132\end{array}$ & Placebo $\mathrm{N}=125$ & $\begin{array}{l}\text { Evolocumab } \\
N=264\end{array}$ & Placebo $\mathrm{N}=178$ & $\begin{array}{l}\text { Evolocumab } \\
N=341\end{array}$ \\
\hline Sex, female, n (\%) & $28(43.8)$ & $58(43.9)$ & $72(57.6)$ & $143(54.2)$ & $95(53.4)$ & $161(47.2)$ \\
\hline $\begin{array}{l}\text { Age, years, mean } \\
\text { (SD) }\end{array}$ & $63.0(8.6)$ & $61.9(8.6)$ & $60.2(8.2)$ & $60.9(8.5)$ & $62.6(8.8)$ & $62.2(8.1)$ \\
\hline $\begin{array}{c}\text { Ethnicity Hispanic/ } \\
\text { Latino, n (\%) }\end{array}$ & $12(18.8)$ & $28(21.2)$ & $29(23.2)$ & $60(22.7)$ & $23(12.9)$ & $55(16.1)$ \\
\hline \multicolumn{7}{|l|}{ Race, n (\%) } \\
\hline White & $40(62.5)$ & $82(62.1)$ & $79(63.2)$ & $165(62.5)$ & $83(46.6)$ & $157(46.0)$ \\
\hline Asian & $15(23.4)$ & $40(30.3)$ & $32(25.6)$ & $73(27.7)$ & $72(40.4)$ & $144(42.2)$ \\
\hline $\begin{array}{c}\text { Black or African } \\
\text { American }\end{array}$ & $7(10.9)$ & $8(6.1)$ & $6(4.8)$ & $11(4.2)$ & $20(11.2)$ & $31(9.1)$ \\
\hline $\begin{array}{l}\text { American Indian or } \\
\text { Alaska native }\end{array}$ & $1(1.6)$ & $1(0.8)$ & $6(4.8)$ & $6(2.3)$ & $0(0.0)$ & $2(0.6)$ \\
\hline $\begin{array}{l}\text { Native Hawaiian } \\
\text { or other Pacific } \\
\text { Islander }\end{array}$ & $0(0.0)$ & $0(0.0)$ & $0(0.0)$ & $1(0.4)$ & $0(0.0)$ & $0(0.0)$ \\
\hline Multiple & $1(1.6)$ & $1(0.8)$ & $2(1.6)$ & $7(2.7)$ & $3(1.7)$ & $6(1.8)$ \\
\hline Other & $0(0.0)$ & $0(0.0)$ & $0(0.0)$ & $1(0.4)$ & $0(0.0)$ & $1(0.3)$ \\
\hline $\begin{array}{l}\mathrm{BMI}, \mathrm{kg} / \mathrm{m}^{2} \text {, mean } \\
(\mathrm{SD})\end{array}$ & $31.2(7.4)$ & $30.2(6.0)$ & $31.2(6.6)$ & $31.6(6.3)$ & $28.8(6.2)$ & $28.4(5.2)$ \\
\hline $\begin{array}{l}\text { Waist circumference, } \\
\text { cm, mean (SD) }\end{array}$ & $103.9(17.2)$ & $103.2(14.4)$ & $104.1(16.6)$ & $104.2(15.7)$ & $96.8(14.4)$ & $97.3(12.8)$ \\
\hline $\begin{array}{l}\text { Duration of diabetes, } \\
\text { years, mean (SD) }\end{array}$ & $9.6(7.51)$ & $10.6(7.80)$ & $9.9(7.52)$ & $10.5(7.18)$ & $10.1(7.75)$ & $10.2(7.60)$ \\
\hline $\begin{array}{l}\text { Fasting serum } \\
\text { glucose, } \mathrm{mmol} / \mathrm{L} \text {, } \\
\text { median }(\mathrm{Q} 1, \mathrm{Q} 3)\end{array}$ & $7.25(6.00,8.85)$ & $7.30(6.20,9.50)$ & $7.50(6.20,9.70)$ & $8.15(6.35,10.50)$ & $6.80(5.80,8.30)$ & $7.00(5.80,8.70)$ \\
\hline $\begin{array}{l}\text { HbA1c (fraction of 1) } \\
\text { median }(\mathrm{Q} 1, \mathrm{Q} 3)\end{array}$ & $\begin{array}{l}0.0690 \\
(0.0640 \\
0.0755)\end{array}$ & $\begin{array}{l}0.0700(0.0645 \\
0.0815)\end{array}$ & $\begin{array}{l}0.0740(0.0640 \\
0.0860)\end{array}$ & $\begin{array}{l}0.0740(0.0655 \\
0.0840)\end{array}$ & $\begin{array}{l}0.0670(0.0620 \\
0.0760)\end{array}$ & $\begin{array}{l}0.0700(0.0630 \\
0.0800)\end{array}$ \\
\hline \multicolumn{7}{|c|}{ Cardiovascular risk category per 2019 ESC/EAS [5] guidelines, n (\%) } \\
\hline Very high risk & $58(90.6)$ & $124(93.9)$ & $116(92.8)$ & $243(92.0)$ & $154(86.5)$ & $303(88.9)$ \\
\hline High risk & $6(9.4)$ & $8(6.1)$ & $9(7.2)$ & $21(8.0)$ & $24(13.5)$ & $38(11.1)$ \\
\hline \multicolumn{7}{|c|}{ Statin use per 2018 ACC/AHA guidelines [21], n (\%) } \\
\hline Any statin use $\mathrm{a}^{\mathrm{a}}$ & $48(75.0)$ & $104(78.8)$ & $95(76.0)$ & $213(80.7)$ & $120(67.4)$ & $216(63.3)$ \\
\hline $\begin{array}{l}\text { High-intensity } \\
\text { statin }\end{array}$ & $12(18.8)$ & $29(22.0)$ & $35(28.0)$ & $67(25.4)$ & $23(12.9)$ & $45(13.2)$ \\
\hline $\begin{array}{l}\text { Moderate-intensity } \\
\text { statin }\end{array}$ & $35(54.7)$ & $71(53.8)$ & $56(44.8)$ & $134(50.8)$ & $93(52.2)$ & $162(47.5)$ \\
\hline Ezetimibe & $1(1.6)$ & $4(3.0)$ & $4(3.2)$ & $7(2.7)$ & $5(2.8)$ & $9(2.6)$ \\
\hline \multicolumn{7}{|l|}{ Lipid concentration } \\
\hline $\begin{array}{l}\mathrm{LDL}-\mathrm{C}, \mathrm{mmol} / \mathrm{L}, \\
\text { mean (SD) }\end{array}$ & $2.811(0.901)$ & $2.737(0.971)$ & $2.508(0.817)$ & $2.599(0.895)$ & $2.539(0.884)$ & $2.511(0.818)$ \\
\hline $\begin{array}{l}\text { Non-HDL-C, } \\
\mathrm{mmol} / \mathrm{L} \text {, mean } \\
(\mathrm{SD})\end{array}$ & 3.819 (0.977) & $3.752(1.004)$ & $3.720(0.933)$ & $3.793(0.985)$ & $3.052(0.926)$ & 3.033 (0.849) \\
\hline $\begin{array}{l}\text { Total ApoB, g/L, } \\
\text { mean (SD) }\end{array}$ & $0.986(0.225)$ & $0.974(0.229)$ & $0.983(0.238)$ & $0.996(0.239)$ & $0.825(0.217)$ & $0.827(0.205)$ \\
\hline $\begin{array}{l}\mathrm{Lp}(\mathrm{a}), \mathrm{nmol} / \mathrm{L}, \\
\quad \text { median }(\mathrm{Q} 1, \mathrm{Q} 3)\end{array}$ & $\begin{array}{l}21.0 \\
7.0,58.0\end{array}$ & $\begin{array}{l}37.0 \\
9.0,128.8\end{array}$ & $\begin{array}{l}29.0 \\
8.0,136.0\end{array}$ & $\begin{array}{l}22.0 \\
8.0,76.0\end{array}$ & $\begin{array}{l}47.0 \\
12.0,128.0\end{array}$ & $\begin{array}{l}33.0 \\
11.5,121.0\end{array}$ \\
\hline $\begin{array}{l}\text { VLDL-C, mmol/L, } \\
\text { median (Q1, Q3) }\end{array}$ & $\begin{array}{l}0.970 \\
(0.830,1.140)\end{array}$ & $\begin{array}{l}0.953 \\
(0.840,1.110)\end{array}$ & $\begin{array}{l}1.040 \\
(0.880,1.335)\end{array}$ & $\begin{array}{l}1.090 \\
(0.910,1.370)\end{array}$ & $\begin{array}{l}0.520 \\
(0.410,0.600)\end{array}$ & $\begin{array}{l}0.520 \\
(0.410,0.645)\end{array}$ \\
\hline
\end{tabular}


Table 1 (continued)

\begin{tabular}{|c|c|c|c|c|c|c|}
\hline \multirow[t]{2}{*}{ Characteristic } & \multicolumn{2}{|c|}{ High TGs and normal HDL-C } & \multicolumn{2}{|c|}{ High TGs and low HDL-C } & \multicolumn{2}{|c|}{ Normal TGs and normal HDL-C } \\
\hline & Placebo $N=64$ & $\begin{array}{l}\text { Evolocumab } \\
\mathrm{N}=132\end{array}$ & Placebo $\mathrm{N}=125$ & $\begin{array}{l}\text { Evolocumab } \\
\mathrm{N}=264\end{array}$ & Placebo $\mathrm{N}=178$ & $\begin{array}{l}\text { Evolocumab } \\
\mathrm{N}=341\end{array}$ \\
\hline $\begin{array}{l}\text { Remnant choles- } \\
\text { terol, mmol/L, } \\
\text { median }(\mathrm{Q} 1, \mathrm{Q} 3)\end{array}$ & $\begin{array}{l}0.965 \\
(0.830,1.125)\end{array}$ & $\begin{array}{l}0.953 \\
(0.840,1.120)\end{array}$ & $\begin{array}{l}1.060 \\
(0.875,1.400)\end{array}$ & $\begin{array}{l}1.100 \\
(0.900,1.370)\end{array}$ & $\begin{array}{l}0.520 \\
(0.420,0.600)\end{array}$ & $\begin{array}{l}0.520 \\
(0.420,0.640)\end{array}$ \\
\hline $\begin{array}{l}\mathrm{TG}, \mathrm{mmol} / \mathrm{L}, \\
\text { median }(\mathrm{Q} 1, \mathrm{Q} 3)\end{array}$ & $\begin{array}{l}2.133 \\
1.815,2.475\end{array}$ & $\begin{array}{l}2.078 \\
1.830,2.445\end{array}$ & $\begin{array}{l}2.300 \\
1.940,3.065\end{array}$ & $\begin{array}{l}2.440 \\
1.975,3.038\end{array}$ & $\begin{array}{l}1.115 \\
0.915,1.300\end{array}$ & $\begin{array}{l}1.140 \\
0.900,1.390\end{array}$ \\
\hline $\begin{array}{l}\mathrm{HDL}-\mathrm{C}, \mathrm{mmol} / \mathrm{L}, \\
\text { mean (SD) }\end{array}$ & $1.353(0.245)$ & $1.343(0.206)$ & $0.947(0.163)$ & $0.935(0.185)$ & $1.488(0.338)$ & $1.440(0.286)$ \\
\hline
\end{tabular}

When the calculated LDL-C was $<1.0 \mathrm{mmol} / \mathrm{L}$ or TGs were $>4.5 \mathrm{mmol} / \mathrm{L}$, calculated LDL-C was replaced with ultracentrifugation to inform $\mathrm{LDL}-\mathrm{C}$ and VLDL-C from the same blood sample, if available

ACC American College of Cardiology, AHA American Heart Association, ApoB apolipoprotein B, BMI body mass index, EAS European Atherosclerosis Society, ESC European Society of Cardiology, HbA1c hemoglobin A1c, HDL-C high-density lipoprotein cholesterol, LDL-C low-density lipoprotein cholesterol, $L p$ (a) lipoprotein(a), non-HDL-C non-high-density lipoprotein cholesterol, $Q$ quartile, $T G$ triglycerides, VLDL-C very low-density lipoprotein cholesterol

a Represents use of statin therapy before initiating any treatment intervention (including atorvastatin and/or study drug); in BANTING, $99.3 \%$ of patients were on moderate- or high-intensity statin at randomization; in BERSON, all patients initiated moderate-intensity atorvastatin at enrollment

\section{Change from baseline}

Significant treatment group differences were observed in the improvement from baseline to the mean of weeks 10 and 12 across all lipid parameters (Additional file 1: Table S3). At the mean of weeks 10 and 12, compared with placebo, evolocumab treatment reduced LDL-C by an LS mean of $1.56 \mathrm{mmol} / \mathrm{L}(95 \%$ CI $1.06,2.05)$ with Q2W dosing and $1.98 \mathrm{mmol} / \mathrm{L}(95 \%$ CI 1.71, 2.24) with QM dosing in the group with high TGs and normal HDLC, $1.74 \mathrm{mmol} / \mathrm{L}(95 \% \mathrm{CI} 1.45,2.02)$ with Q2W dosing and $1.66 \mathrm{mmol} / \mathrm{L}(95 \% \mathrm{CI} 1.49,1.83)$ with QM dosing in the group with high TGs and low HDL-C, and $1.62 \mathrm{mmol} / \mathrm{L}$ (95\% CI 1.38, 1.87) with Q2W dosing and $1.57 \mathrm{mmol} / \mathrm{L}$ (95\% CI 1.40, 1.73) with QM dosing in the group with normal TGs and normal HDL-C, all $P$-values $<0.0001$. Compared with placebo, evolocumab treatment reduced non-HDL-C by an LS mean of $1.70 \mathrm{mmol} / \mathrm{L}$ (95\% CI 1.16, 2.23) with Q2W dosing and $2.47 \mathrm{mmol} / \mathrm{L}$ (95\% CI 2.16, 2.78) with QM dosing in the group with high TGs and normal HDL-C, $2.14 \mathrm{mmol} / \mathrm{L}$ (95\% CI 1.76, 2.53) with Q2W dosing and $1.98 \mathrm{mmol} / \mathrm{L}(95 \% \mathrm{CI} 1.79,2.18)$ with QM dosing in the group with high TGs and low HDL-C, and $1.78 \mathrm{mmol} / \mathrm{L}(95 \% \mathrm{CI} 1.52,2.04)$ with Q2W dosing and $1.67 \mathrm{mmol} / \mathrm{L}(95 \% \mathrm{CI} 1.49,1.84)$ with QM dosing in the group with normal TGs and normal HDL-C, all $P$-values $<0.0001$.

At week 12, compared with placebo, evolocumab treatment reduced ApoB by an LS mean of $0.42 \mathrm{~g} / \mathrm{L}(95 \% \mathrm{CI}$ $0.27,0.56)$ with Q2W dosing and $0.55 \mathrm{~g} / \mathrm{L}$ (95\% CI 0.48 , 0.62 ) with $\mathrm{QM}$ dosing in the group with high TGs and normal HDL-C, 0.56 g/L (95\% CI 0.46, 0.66) with Q2W dosing and $0.40 \mathrm{~g} / \mathrm{L}(95 \% \mathrm{CI} 0.34,0.45)$ with QM dosing in the group with high TGs and low HDL-C, and $0.45 \mathrm{~g} / \mathrm{L}$ (95\% CI $0.38,0.52)$ with Q2W dosing and $0.36 \mathrm{~g} / \mathrm{L}(95 \%$
CI $0.31,0.40$ ) with QM dosing in the group with normal TGs and normal HDL-C, all $P$-values $<0.0001$.

Greater reductions from baseline for evolocumab than placebo were also observed at the mean of weeks 10 and 12 in all groups for $L p(a)$, VLDL-C, remnant cholesterol and TGs (all $P$-values $<0.0001$ except for VLDL-C in the group with high TGs and normal HDL-C, $\mathrm{P}=0.0002$ ). For HDL-C, small, but significant mean treatment differences favoring evolocumab were observed in patients with high TGs, except in the normal TGs and normal HDL-C group with Q2W dosing even though there were similar mean absolute changes from baseline in the evolocumab Q2W and QM groups.

\section{Correlation of changes in ApoB100 with non-HDL-C, remnant cholesterol and TGs}

In the evolocumab-treated individuals with $\mathrm{Q} 2 \mathrm{~W}$ and QM dosing combined, changes in ApoB100 from baseline to the mean of weeks 10 and 12 were strongly correlated with changes in non-HDL-C from baseline to the mean of weeks 10 and 12 (overall $r=0.93, \mathrm{P}<0.0001$ ). The strong correlation existed in all three subgroups: the group with high TGs and normal HDL-C $(r=0.92$, $\mathrm{P}<0.0001$ ); the group with high TGs and low HDL-C $(\mathrm{r}=0.89, \mathrm{P}<0.0001)$; the group with normal TGs and normal HDL-C $(r=0.93, \mathrm{P}<0.0001)$ (Fig. 3). The changes in ApoB100 from baseline to the mean of weeks 10 and 12 were moderately correlated with changes in remnant cholesterol (overall $\mathrm{r}=0.45, \mathrm{P}<0.0001$ ). The moderate correlations persisted in all three subgroups: the group with high TGs and normal HDL-C $(\mathrm{r}=0.49, \mathrm{P}<0.0001)$; the group with high TGs and low HDL-C $(r=0.51$, $\mathrm{P}<0.0001)$; the group with normal $\mathrm{TG}$ and normal HDL-C $(r=0.41, P<0.0001)$. The correlation with TGs 


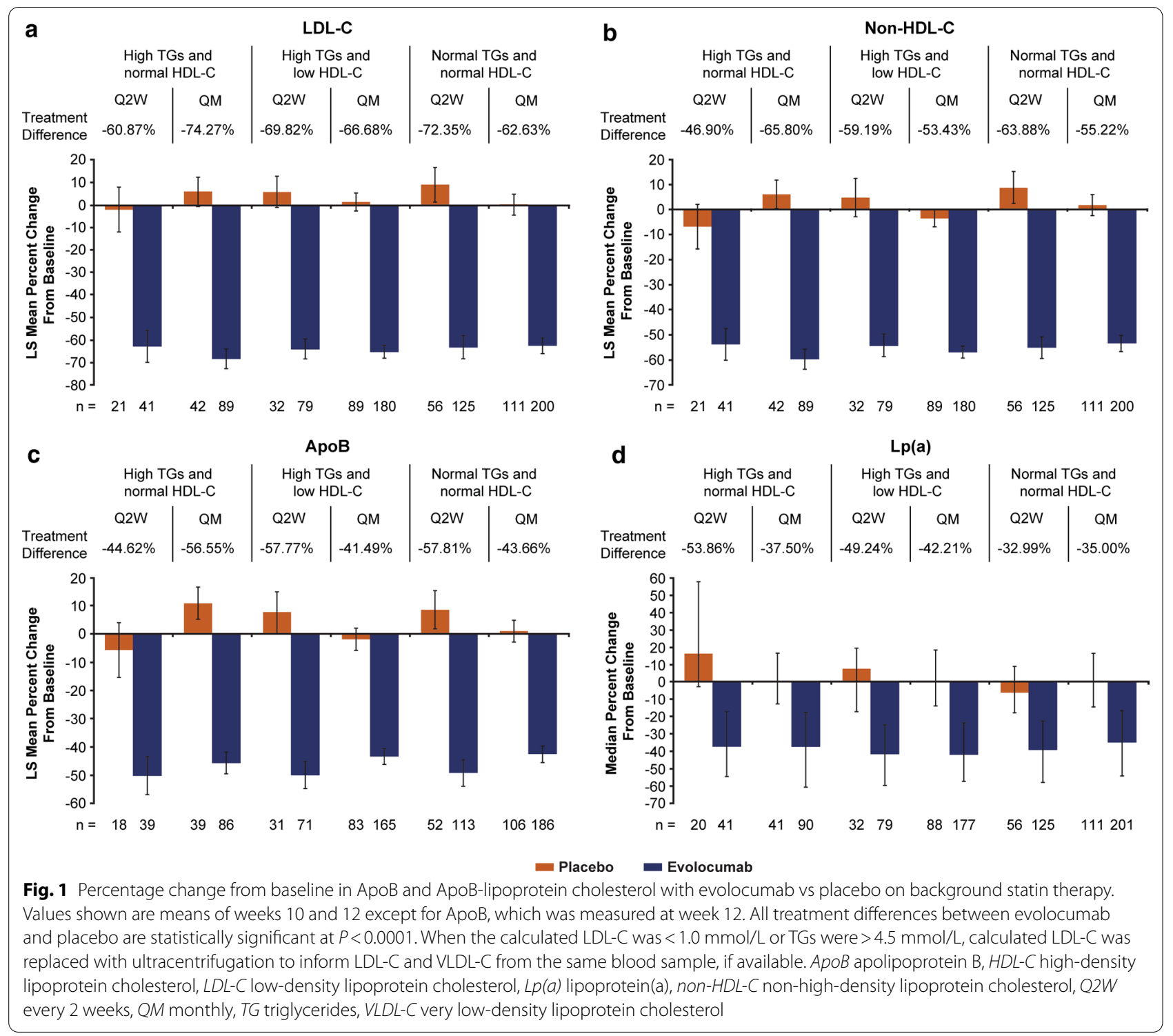

was moderate in the group with high TGs and normal HDL-C $(r=0.49, \mathrm{P}<0.0001)$, and weaker in the other two groups (Fig. 3).

\section{Goal attainment}

The differences in the percentages of individuals who attained the 2019 ESC/EAS lipid treatment goals in the evolocumab-treated vs placebo-treated groups were substantial and significant for all goals measured (Fig. 4 and Additional file 1: Table S4). For the goal combining 50\% LDL-C reduction plus attainment of $\mathrm{LDL}-\mathrm{C}<1.4 \mathrm{mmol} / \mathrm{L}$ at the mean of weeks 10 and 12 , more evolocumab- than placebo-treated individuals were able to meet the goal in the high TGs and normal HDL-C group (treatment difference [evolocumab minus placebo]: Q2W, 75.6\%; QM, 79.8\%), the high TGs and

(See figure on next page.)

Fig. 2 Percentage change from baseline in VLDL-C, remnant cholesterol and TGs with evolocumab vs placebo in participants with high TGs with or without $A D$ on background statin therapy. All treatment differences between evolocumab and placebo are statistically significant at $P<0.0001$ except for VLDL-C in the group with high TGs and normal HDL-C ( $P=0.0002)$. HDL-C high-density lipoprotein cholesterol, TG triglycerides, VLDL-C very low-density lipoprotein cholesterol 

Treatment High TGs and normal HDL-C $-16.14 \%$ Difference

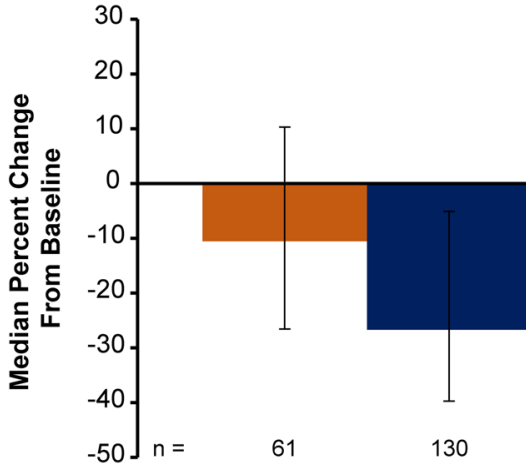

b

$$
\text { Treatment }
$$

High TGs and normal HDL-C $-28.89 \%$
130

\section{VLDL-C}

High TGs and low HDL-C $-19.56 \%$
Normal TGs and normal HDL-C $-15.00 \%$

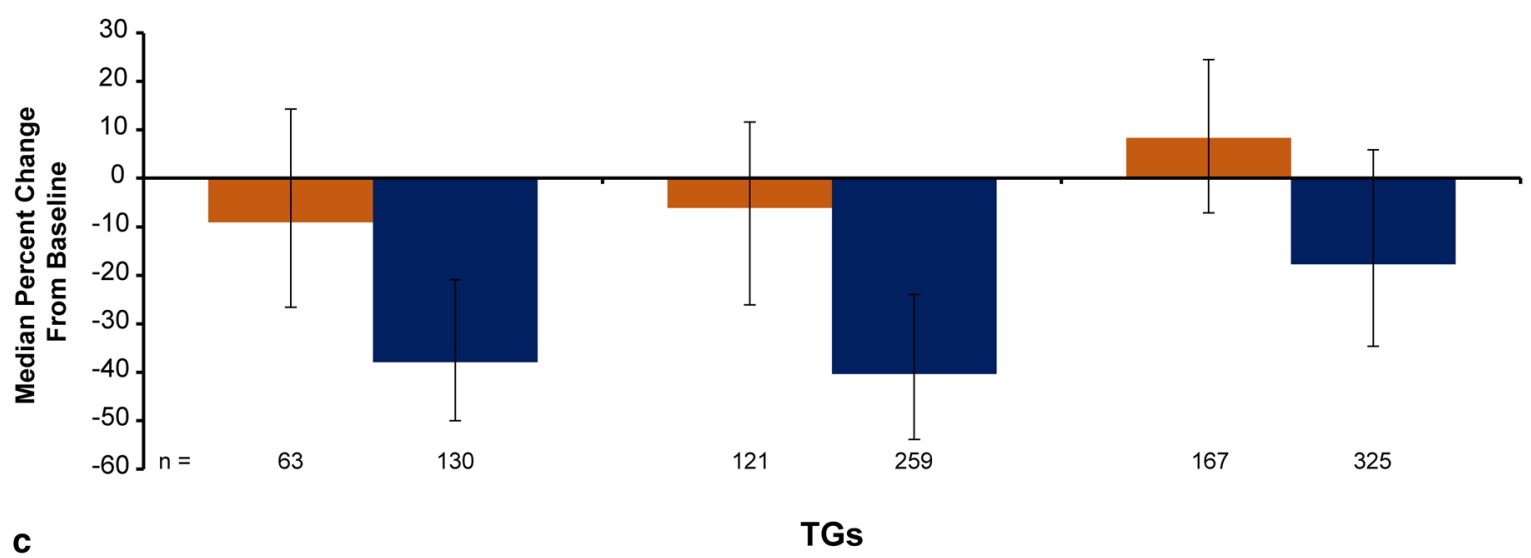

High TGs and normal HDL-C

Treatment Difference

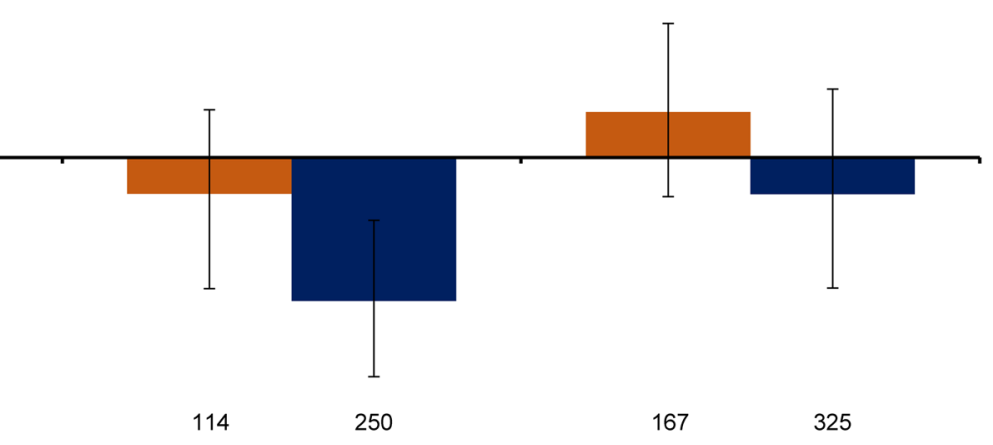

Remnant cholesterol

High TGs and low HDL-C $-34.20 \%$
Normal TGs and normal HDL-C $-25.98 \%$

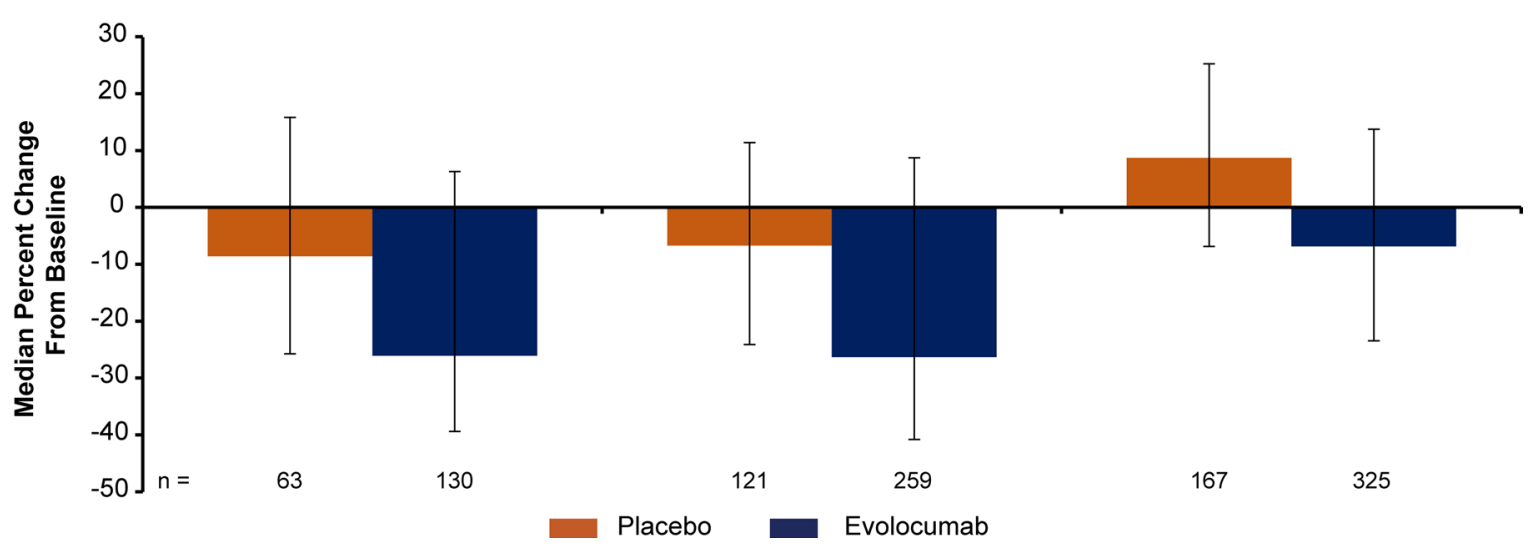




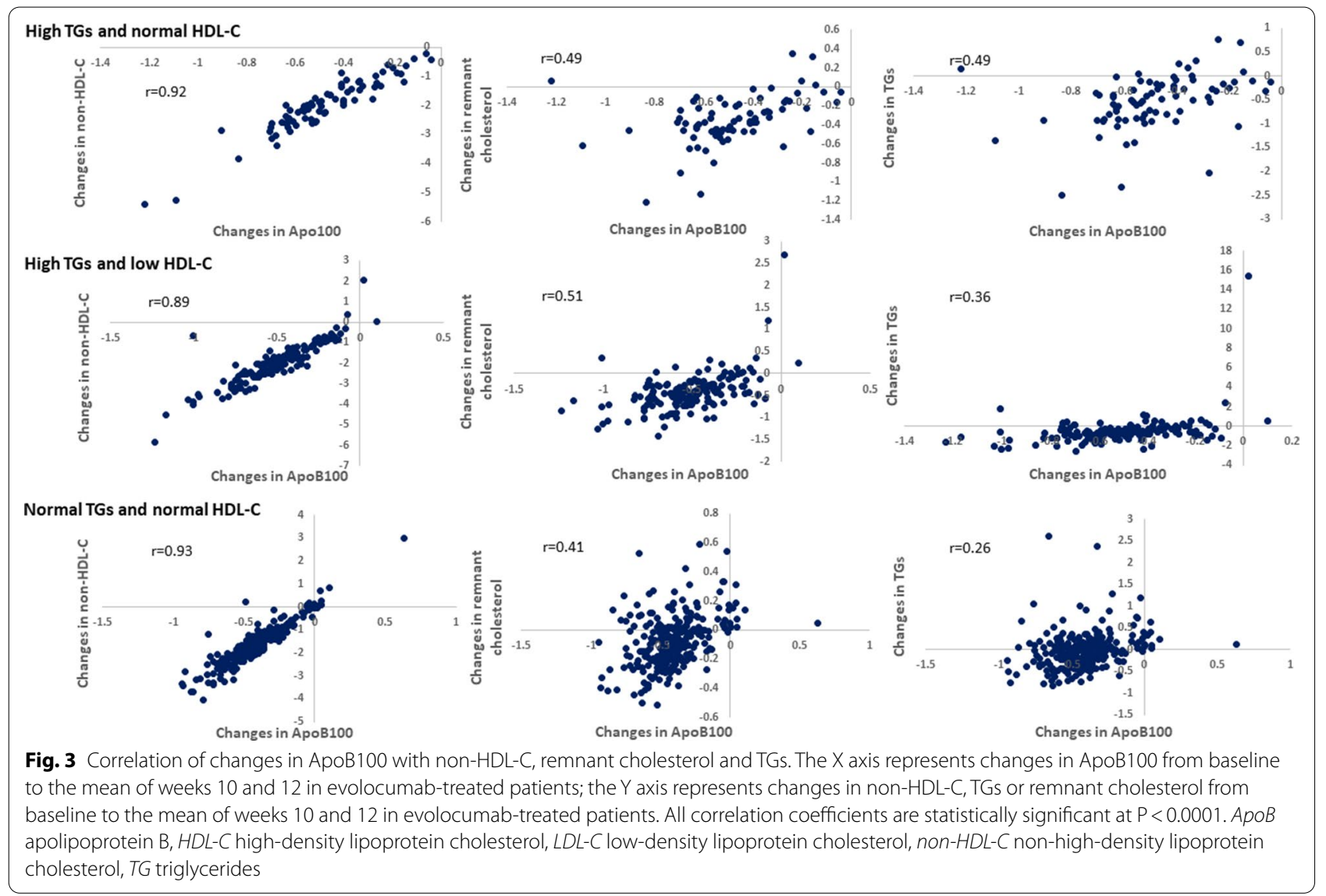

low HDL-C group (treatment difference [evolocumab minus placebo]: Q2W, 74.7\%; QM, 77.8\%), and the normal group (treatment difference [evolocumab minus placebo]: Q2W, 75.2\%; QM, 75.1\%), all $P$-values $<0.0001$. Similarly, for the LDL-C goals of at least $50 \%$ response, $\mathrm{LDL}-\mathrm{C}<1.4 \mathrm{mmol} / \mathrm{L}$, and $\mathrm{LDL}-\mathrm{C}<1.0 \mathrm{mmol} / \mathrm{L}$, a greater percentage of evolocumab- than placebo-treated individuals attained each goal for all three groups and dosing regimens, all $P$-values $<0.0001$.

For the goals of reduction of non-HDL-C to $<2.6 \mathrm{mmol} / \mathrm{L}$ and $<2.2 \mathrm{mmol} / \mathrm{L}$ at the mean of weeks 10 and 12, a greater percentage of individuals treated with evolocumab than placebo attained the goals in each group and each dosing regimen, (all $P$-values $<0.0001$ ). Similarly, for the goals of reduction of ApoB to $<80 \mathrm{mg} /$
$\mathrm{dL}$ and $<65 \mathrm{mg} / \mathrm{dL}$ at week 12 , a greater percentage of individuals treated with evolocumab than placebo attained the goals, regardless of the group or dosing regimen (all $P$-values $<0.0001)$.

\section{Discussion}

This pooled analysis of data from two phase 3 , dedicated T2DM studies demonstrated that both dosing regimens of evolocumab consistently and effectively reduced $A p o B$ and the cholesterol levels from ApoB-containing lipoproteins, as reflected by the reduction in non-HDL-C levels, across individuals with high TGs with and without AD.

$\mathrm{AD}$ increases CVD risk and is a common condition in patients with T2DM. In this analysis, approximately half of individuals with T2DM and elevated LDL-C had high

(See figure on next page.)

Fig. 4 Percentage of participants who achieved each lipid treatment goal with evolocumab vs placebo on background statin therapy. Values shown are means of weeks 10 and 12 except for ApoB, which was measured at week 12. The treatment differences between evolocumab and placebo for all endpoints are statistically significant at $P<0.0001$ based on Cochran-Mantel-Haenszel tests stratified by study. When the calculated $\mathrm{LDL}-\mathrm{C}$ was $<1.0 \mathrm{mmol} / \mathrm{L}$ or TGs were $>4.5 \mathrm{mmol} / \mathrm{L}$, calculated LDL-C was replaced with ultracentrifugation to inform LDL-C and VLDL-C from the same blood sample, if available. $A p o B$ apolipoprotein $B, B L$ baseline, $L D L-C$ low-density lipoprotein cholesterol, non- $H D L-C$ non-high-density lipoprotein cholesterol, Q2W every 2 weeks, QM monthly, TGs triglycerides 


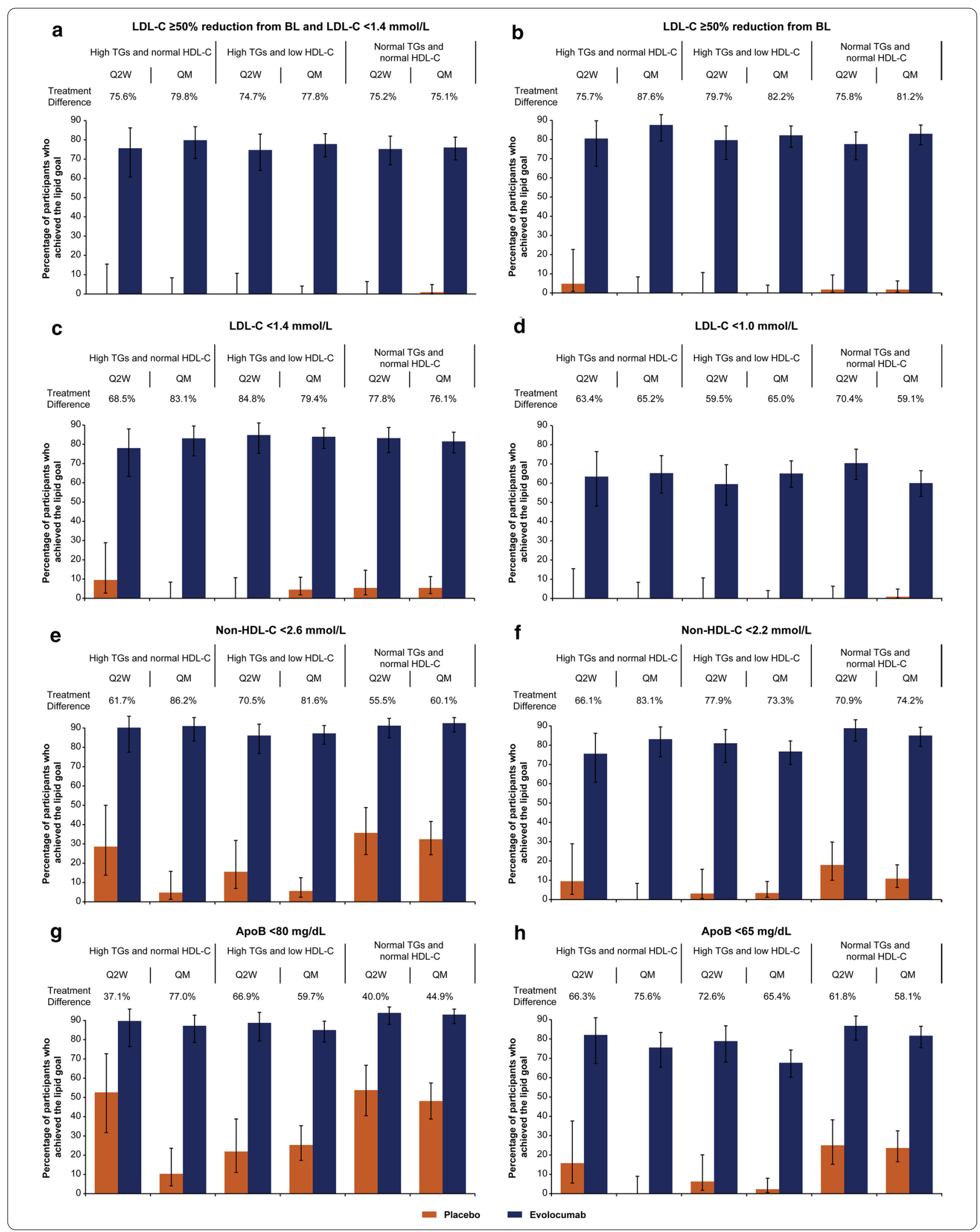


TGs at baseline. Among these individuals, $66.5 \%$ had AD (high TGs and low HDL-C). As expected, baseline nonHDL-C, ApoB, VLDL-C, and remnant cholesterol were higher in the groups of participants with high TGs than in the group with normal TGs. At the same time, among individuals with high TGs, baseline LDL-C was lower in the group with AD.

\section{Reduction in ApoB and cholesterol carried by $A$ poB-containing lipoproteins}

In individuals with high TGs with and without $\mathrm{AD}$ treated with at least moderate-intensity statin, the addition of evolocumab (Q2W or QM), compared to placebo, significantly reduced mean LDL-C by $66.7 \%$ to $74.3 \%$, non-HDL-C by $53.4 \%$ to $65.8 \%$, and ApoB by $41.5 \%$ to 56.6\% (all $P$-values $<0.0001$ ). Results were similar in the group of individuals with normal TGs. This is the first analysis reporting the effect of evolocumab in individuals with high TGs with and without AD. The results are consistent with prior evolocumab studies in primary hyperlipidemia [33, 34] and in type 2 diabetes from the BANTING [25] and BERSON [24] studies. While the BANTING and BERSON studies did not measure LDL particle (LDL-P) number and size, Toth et al. have previously shown that in a broad range of patients with hyperlipidemia, treatment with evolocumab reduced both large and small LDL-P. The percentage reduction in large LDL-P was approximately twice that in small LDL$P$, which may manifest less efficient clearance of small, dense LDL-P by the LDL-R. The reported percentage reduction in total LPL-P and small LDL-P in the subset of patients with T2D were similar to the overall population [35]. In the open-label ODYSSEY DM-DYSLIPIDEMIA study (NCT02642159) in participants with T2DM and mixed dyslipidemia, alirocumab, another PCSK9i, significantly reduced all three lipid parameters (LDL-C, nonHDL-C, and ApoB) and LDL-P number when compared with usual care.

We found a robust correlation between ApoB100 and non-HDL-C with evolocumab treatment. This observation is consistent with prior reports [36,37] and clinically meaningful because both non-HDL-C and ApoB are considered secondary goals to adjust further or intensify the lipid-lowering therapy $[5,20]$. Of note, non-HDL-C can be easily calculated from the routine lipid panel (TC minus HDL-C) with no added cost. Both ApoB and nonHDL-C are also recommended to improve ASCVD risk assessment, particularly in situations where discordance between these measures and LDL-C may occur (e.g. diabetes mellitus, obesity, metabolic syndrome, high TGs, and very low LDL-C levels). The moderate positive correlation of ApoB100 with remnant cholesterol and the weaker correlation with TGs may be explained by the fact that most ApoB100 is from LDL particles. In contrast, remnant cholesterol and TGs represent the content from TRL (excludes LDL).

We have also investigated the associations between evolocumab treatment and $\mathrm{Lp}$ (a) across all three groups. Because a positive correlation has been reported between higher Lp(a) levels and the development of ASCVD, and about $90 \%$ of Lp(a) levels are inherited, the 2019 ESC/ EAS guidelines recommend that its measurement should be considered in each person's lifetime [5]. Statins often increase Lp(a) levels [38], which is aligned with the changes observed in the placebo groups. In our high-risk patient population with high TGs, with a median Lp(a) at baseline that ranged from $21.0 \mathrm{nmol} / \mathrm{L}$ to $37.0 \mathrm{nmol} / \mathrm{L}$, evolocumab was associated with a significant reduction of $\operatorname{Lp}(\mathrm{a})$, by a median of $37.5 \%$ to $53.9 \%$.

Our analyses' findings are important because reducing ApoB levels and the cholesterol content across all the spectrum of ApoB lipoproteins (in addition to LDLC) represents an opportunity to address the residual ASCVD risk that still exists in many patients with T2DM despite normal LDL-C levels and receiving optimal statin therapy [20]. Recently, an analysis performed from a Danish contemporary population-based cohort excluding individuals with a history of myocardial infarction at baseline and receiving lipid-lowering therapy, the hazard ratio for myocardial infarction per a $100 \mathrm{mg} / \mathrm{dL}$ higher concentration of ApoB was 2.21 (95\% CI 1.90 to 2.58) [39].

\section{Triglycerides and cholesterol content on TRL and their remnants}

Remnant lipoproteins (chylomicron remnants, VLDL, and IDL) are smaller cholesterol-enriched particles that, via intimal deposition of cholesterol, may contribute to atherogenesis and the residual ACVD risk [40]. A simple way to estimate remnant cholesterol levels is by subtracting LDL-C and HDL-C to total cholesterol. In individuals with high TGs with and without $\mathrm{AD}$ receiving statin therapy, remnant cholesterol levels, which are commonly elevated in patients with T2DM and are a maker of elevated TGs in plasma, were significantly reduced with evolocumab by a median of $28.9 \%$ to $34.2 \%$ compared with placebo (all $P$-values $<0.0001$ ). VLDL-C and TGs levels were also significantly reduced with evolocumab in individuals with high TGs with and without AD compared to placebo (all $P$-values $<0.0001$ except for VLDL-C in the group with high TGs and normal HDL-C, $\mathrm{P}=0.0002$ ). The reductions in remnant cholesterol, VLDL-C, and TGs in individuals with normal TGs were also significant, albeit the magnitude of the percentage change from baseline was clearly lower compared with individuals with high TGs. This is expected as the baseline levels of these 
lipid parameters were lower than those with high TGs. Interestingly, Sharma et al. demonstrated that in individuals with mixed dyslipidemia, higher baseline VLDL-C levels were associated with a greater percentage decrease in TGs following 12 weeks of lipid-lowering therapy [41]. The higher percentage reduction in non-HDL-C and ApoB when compared with VLDL-C and remnant cholesterol is expected because the calculation of non-HDL$\mathrm{C}$ and the measurement of ApoB levels also account for LDL-C, and Lp(a) and LDL particles, respectively.

The significant improvement in the lipid profile (LDLC, non-HDL-C, ApoB, VLDL-C, remnant cholesterol, and TGs) of individuals with T2DM with or without AD treated with evolocumab could be explained by the increase in the LDL receptor (LDLR) expression in the liver, which recognizes both ApoB100 on LDL and ApoE on VLDL and IDL. A recent study [42] performed in individuals with $\mathrm{T} 2 \mathrm{D}$ showed a significant increase in the fractional catabolic rate (FCR) for smaller VLDLapoB100 and -triglyceride and a 54\% increase in the overall FCR of IDL with 12 weeks of treatment with evolocumab. Of note, ApoE is also a ligand for low-density lipoprotein receptor-related protein 1 (LRP1). Since in vitro studies $[43,44]$ have shown the ability of PCSK9 to also modulate the expression in the liver of VLDL receptor, LRP1, and ApoE receptor, we cannot completely rule out an effect of PCSK9 inhibition on these metabolic pathways for the observed reduction of VLDL$\mathrm{C}$ and IDL-C.

\section{Lipid treatment goals attainment}

The participants in this analysis represent a population in which a vast majority had a very high risk of CVD events. For such individuals, the ESC/EAS 2019 dyslipidemia guidelines recommend an LDL-C goal of $<1.4 \mathrm{mmol} / \mathrm{L}$, at least a $50 \%$ reduction from baseline in LDL-C, and secondary goals of nonHDL-C $<2.2 \mathrm{mmol} / \mathrm{L}$ and $\mathrm{ApoB}<65 \mathrm{mg} / \mathrm{dL}$. Similar aggressive goals are recommended by the American Association of Clinical Endocrinologists and the American College of Endocrinology [20] in patients with diabetes and ASCVD. Our analysis shows that the recommended goals for high-risk patients are attainable when a PCSK9i is added to background statin therapy. Evolocumab enabled the majority of individuals with and without high TGs $(74.7 \%$ to $79.8 \%)$ to achieve both an LDL-C goal of $<1.4 \mathrm{mmol} / \mathrm{L}$ and an $\mathrm{LDL}-\mathrm{C}$ reduction of at least $50 \%$. More than $68 \%$ achieved each separately. By contrast, in a recent Italian registry [45], only $3.2 \%$ of 4751 patients with very high CVD risk attained the combined LDL-C goal, despite $55 \%$ of patients receiving high-intensity statins $(4.8 \%$ received ezetimibe). The DA VINCI study [46], a cross-sectional study that collected data from 18 European countries, showed that less than $30 \%$ of patients at high- or very high-risk receiving high-intensity statin monotherapy or a statin in combination with ezetimibe attained their 2019 ESC/EAS risk-based LDL-C goal. Notably, an $\mathrm{LDL}-\mathrm{C}<1.0 \mathrm{mmol} / \mathrm{L}$, which may be considered for patients with a recurrent vascular event within 2 years, was achieved by $59.1 \%$ to $70.4 \%$ of individuals with and without high TGs who received evolocumab, compared with placebo (only one individual reached an LDL-C of less than $1.4 \mathrm{mmol} / \mathrm{L}$ ), on top of statin therapy. In addition, more than $75 \%$ of evolocumab-treated individuals achieved the non-HDL-C goal of less than $2.2 \mathrm{mmol} / \mathrm{L}$ compared with less than $18 \%$ of placebo-treated individuals. ApoB less than $65 \mathrm{mg} / \mathrm{dL}$ was achieved by more than $67 \%$ of individuals at week 12 compared with $25 \%$ or less of placebo-treated individuals.

Limitations include the post hoc analysis of the data and the short duration of the two studies. Also, most of the participants were Caucasians and Asians, with only a minority identified as Hispanic/Latino or Black or African American.

\section{Conclusions}

In conclusion, in individuals with T2DM with or without $\mathrm{AD}$ receiving background statin therapy, evolocumab significantly reduced LDL-C, non-HDL-C, ApoB, Lp(a), VLDL-C, and remnant cholesterol. Also, evolocumab Q2W or QM enabled a majority of individuals at high/ very-high cardiovascular disease risk to achieve the LDL$C$, non-HDL-C, and ApoB goals recommended by the 2019 ESC/EAS dyslipidemia guidelines.

\section{Abbreviations \\ AD: Atherogenic dyslipidemia; ApoB: Apolipoprotein B; ASCVD: Atherosclerotic cardiovascular disease; Cl: Confidence interval; CVD: Cardiovascular disease; EAS: European Atherosclerosis Society; ESC: European Society of Cardiology; FCR: Fractional catabolic rate; HDL: High-density lipoprotein; IDL: Interme- diate-density lipoprotein; LDL: Low-density lipoprotein; LDL-P: LDL particle; LDLR: LDL receptor; Lp(a): Lipoprotein(a); LRP1: Lipoprotein receptor-related protein 1; LS: Least squares; PCSK9: Proprotein convertase subtilisin/kexin type 9 inhibitor; Q2W: Every 2 weeks; QM: Monthly; SC: Subcutaneous; T2DM: Type 2 diabetes mellitus; TG: Triglycerides; TRL: Triglyceride-rich lipoprotein; VLDL: Very-low-density lipoprotein}

\section{Supplementary Information}

The online version contains supplementary material available at https://doi. org/10.1186/s12933-021-01287-6.

Additional file 1: Table S1. Patient demographic and disease characteristics at baseline by treatment group and dosing regimen. Table S2. Percentage change from baseline lipid values with evolocumab vs placebo treatment (mean of weeks 10 and 12). Table S3. Change from baseline lipid values with evolocumab vs placebo treatment (mean of weeks 10 
and 12). Table S4. Percentage of patients who met each lipid goal with evolocumab vs placebo treatment (mean of weeks 10 and 12).

\section{Acknowledgments}

Ellen Stoltzfus, PhD and Shannon Rao, PhD (Amgen Inc., Thousand Oaks, CA) provided medical writing support for this manuscript.

\section{Authors' contributions}

AJL, JAGL, HW, and MLM contributed to the conception and design of the analysis. HW performed the statistical analysis. All authors contributed to interpretation of the data and critically reviewed and edited the manuscript. In addition, AJL and RSR were investigators in BERSON and BANTING, respectively, and contributed to data acquisition. All authors read and approved the final manuscript.

\section{Funding}

This study was funded by Amgen Inc. The study sponsor was involved in the design, analysis, and interpretation of data and the provision of medical writing support.

\section{Availability of data and materials}

Qualified researchers may request data from Amgen clinical studies. Complete details are available at https://wwwext.amgen.com/science/clinical-trials/clini cal-data-transparency-practices/clinical-trial-data-sharing-request.

\section{Declarations}

\section{Ethics approval and consent to participate}

As noted in the primary reports of the BERSON [24, 29] and BANTING [25] studies, all participants gave informed consent to participate, and the study protocols and amendments were approved by the appropriate ethics review boards at each study site.

\section{Consent for publication}

Not applicable.

\section{Competing interests}

AJ Lorenzatti was the Principal Investigator in the BERSON trial and reports research support from Amgen, Novo Nordisk and Esperion; a consulting role for Amgen, Kowa, and PTC; and speaking activities with Amgen, Novo Nordisk, Pfizer, and PTC. RS Rosenson reports research support from Amgen, Novartis, $\mathrm{NIH}$, and Regeneron; consulting/advisory roles for Amgen, Amyrt C5, CVS Caremark, The Medicines Company, Novartis, Regeneron, and 89 BioMedicines Company; speaking (non-promotional) roles with Amgen, Kowa, and Regeneron; stock holdings with MediMergent; royalties from Wolters Kluwer (UpToDate); and patents for biocellular inflammatory pathways. ML Monsalvo, JAG López, and HWang are employees and shareholders of Amgen.

\section{Author details}

${ }^{1}$ Clinical Research and Cardiology, Instituto Médico DAMIC/Fundación Rusculleda, Córdoba, Argentina. ${ }^{2}$ Amgen Inc, Thousand Oaks, CA, USA. ${ }^{3}$ Amgen Inc, Newbury Park, CA, USA. ${ }^{4}$ Icahn School of Medicine At Mount Sinai, New York, NY, USA.

\section{Received: 28 December 2020 Accepted: 24 April 2021}

Published online: 30 April 2021

\section{References}

1. Austin MA, King MC, Vranizan KM, Krauss RM. Atherogenic lipoprotein phenotype. A proposed genetic marker for coronary heart disease risk. Circulation. 1990;82(2):495-506

2. Lorenzatti AJ, Toth PP. New perspectives on atherogenic dyslipidaemia and cardiovascular disease. Eur Cardiol Rev. 2020;15:1-9.

3. Garvey WT, Kwon S, Zheng D, Shaughnessy S, Wallace P, Hutto A, Pugh $\mathrm{K}$, Jenkins AJ, Klein RL, Liao Y. Effects of insulin resistance and type 2 diabetes on lipoprotein subclass particle size and concentration determined by nuclear magnetic resonance. Diabetes. 2003;52(2):453-62.

4. Halcox JP, Banegas JR, Roy C, Dallongeville J, De Backer G, Guallar E, Perk J, Hajage D, Henriksson KM, Borghi C. Prevalence and treatment of atherogenic dyslipidemia in the primary prevention of cardiovascular disease in Europe: EURIKA, a cross-sectional observational study. BMC Cardiovasc Disord. 2017;17(1):160.

5. Mach F, Baigent C, Catapano AL, Koskinas KC, Casula M, Badimon L, Chapman MJ, De Backer GG, Delgado V, Ference BA, et al. 2019 ESC/EAS Guidelines for the management of dyslipidaemias: lipid modification to reduce cardiovascular risk. Eur Heart J. 2020;41(1):111-88.

6. Jørgensen AB, Frikke-Schmidt R, West AS, Grande P, Nordestgaard BG, Tybjærg-Hansen A. Genetically elevated non-fasting triglycerides and calculated remnant cholesterol as causal risk factors for myocardial infarction. Eur Heart J. 2013;34(24):1826-33.

7. Joshi PH, Khokhar AA, Massaro JM, Lirette ST, Griswold ME, Martin SS, Blaha MJ, Kulkarni KR, Correa A, D'Agostino RB, et al. Remnant lipoprotein cholesterol and incident coronary heart disease: The Jackson Heart and Framingham Offspring Cohort Studies. J Am Heart Assoc. 2016;5(5):e002765.

8. Miller M, Cannon CP, Murphy SA, Qin J, Ray KK, Braunwald E. Impact of triglyceride levels beyond low-density lipoprotein cholesterol after acute coronary syndrome in the PROVE IT-TIMI 22 trial. J Am Coll Cardiol. 2008;51(7):724-30.

9. Nordestgaard BG. Triglyceride-rich lipoproteins and atherosclerotic cardiovascular disease: new insights from epidemiology, genetics, and biology. Circ Res. 2016;118(4):547-63.

10. Sarwar N, Danesh J, Eiriksdottir G, Sigurdsson G, Wareham N, Bingham S, Boekholdt SM, Khaw KT, Gudnason V. Triglycerides and the risk of coronary heart disease: 10,158 incident cases among 262,525 participants in 29 Western prospective studies. Circulation. 2007;115(4):450-8.

11. Varbo A, Freiberg JJ, Nordestgaard BG. Extreme nonfasting remnant cholesterol vs extreme LDL cholesterol as contributors to cardiovascular disease and all-cause mortality in 90000 individuals from the general population. Clin Chem. 2015;61(3):533-43.

12. Yusuf S, Hawken S, Ounpuu S, Dans T, Avezum A, Lanas F, McQueen M, Budaj A, Pais P, Varigos J, et al. Effect of potentially modifiable risk factors associated with myocardial infarction in 52 countries (the INTERHEART study): case-control study. Lancet. 2004;364(9438):937-52.

13. Barter PJ, Ballantyne CM, Carmena R, Castro Cabezas M, Chapman MJ, Couture P, de Graaf J, Durrington PN, Faergeman O, Frohlich J, et al. Apo $B$ versus cholesterol in estimating cardiovascular risk and in guiding therapy: report of the thirty-person/ten-country panel. J Intern Med. 2006;259(3):247-58

14. Langsted A, Madsen CM, Nordestgaard BG. Contribution of remnant cholesterol to cardiovascular risk. J Intern Med. 2020;288(1):116-27.

15. Nicholls SJ, Puri R, Anderson T, Ballantyne CM, Cho L, Kastelein JJ, Koenig W, Somaratne $\mathrm{R}$, Kassahun $\mathrm{H}$, Yang J, et al. Effect of evolocumab on progression of coronary disease in statin-treated patients: the GLAGOV randomized clinical trial. JAMA. 2016;316(22):2373-84.

16. Schwartz GG, Abt M, Bao W, DeMicco D, Kallend D, Miller M, Mundl H, Olsson AG. Fasting triglycerides predict recurrent ischemic events in patients with acute coronary syndrome treated with statins. J Am Coll Cardiol. 2015;65(21):2267-75.

17. Sirimarco G, Labreuche J, Bruckert E, Goldstein LB, Fox KM, Rothwell PM, Amarenco P. Atherogenic dyslipidemia and residual cardiovascular risk in statin-treated patients. Stroke. 2014;45(5):1429-36.

18. Takata K, Nicholls SJ. Tackling residual atherosclerotic risk in statin-treated adults: focus on emerging drugs. Am J Cardiovas Drugs Drugs Devices Intervent. 2019;19(2):113-31.

19. Cosentino F, Grant PJ, Aboyans V, Bailey CJ, Ceriello A, Delgado V, Federici M, Filippatos G, Grobbee DE, Hansen TB, et al. 2019 ESC Guidelines on diabetes, pre-diabetes, and cardiovascular diseases developed in collaboration with the EASD. Eur Heart J. 2020;41(2):255-323.

20. Garber AJ, Handelsman Y, Grunberger G, Einhorn D, Abrahamson MJ, Barzilay JI, Blonde L, Bush MA, DeFronzo RA, Garber JR, et al. Consensus statement by the American Association of Clinical Endocrinologists and American College of Endocrinology on the comprehensive type 2 diabetes management algorithm-2020 executive summary. Endocr Pract 2020:26(1):107-39. 
21. Grundy SM, Stone NJ, Bailey AL, Beam C, Birtcher KK, Blumenthal RS, Braun LT, de Ferranti S, Faiella-Tommasino J, Forman DE, et al. 2018 AHA/ ACC/AACVPR/AAPA/ABC/ACPM/ADA/AGS/APhA/ASPC/NLA/PCNA Guideline on the Management of Blood Cholesterol: A Report of the American College of Cardiology/American Heart Association Task Force on Clinical Practice Guidelines. Circulation. 2019;139(25):e1082-143.

22. Leiter LA, Lundman P, da Silva PM, Drexel H, Jünger C, Gitt AK. Persistent lipid abnormalities in statin-treated patients with diabetes mellitus in Europe and Canada: results of the Dyslipidaemia International Study. Diabet Med. 2011;28(11):1343-51.

23. Breuker C, Clement F, Mura T, Macioce V, Castet-Nicolas A, Audurier Y, Boegner C, Morcrette E, Jalabert A, Villiet M, et al. Non-achievement of LDL-cholesterol targets in patients with diabetes at very-high cardiovascular risk receiving statin treatment: Incidence and risk factors. Int J Cardiol. 2018;268:195-9.

24. Lorenzatti AJ, Eliaschewitz FG, Chen Y, Lu J, Baass A, Monsalvo ML, Wang N, Hamer AW, Ge J. Randomised study of evolocumab in patients with type 2 diabetes and dyslipidaemia on background statin: Primary results of the BERSON clinical trial. Diab Obes Metab. 2019;21(6):1455-63.

25. Rosenson RS, Daviglus ML, Handelsman Y, Pozzilli P, Bays H, Monsalvo ML, Elliott-Davey M, Somaratne R, Reaven P. Efficacy and safety of evolocumab in individuals with type 2 diabetes mellitus: primary results of the randomised controlled BANTING study. Diabetologia. 2019;62(6):948-58.

26. Sabatine MS, Leiter LA, Wiviott SD, Giugliano RP, Deedwania P, De Ferrari GM, Murphy SA, Kuder JF, Gouni-Berthold I, Lewis BS, et al. Cardiovascular safety and efficacy of the PCSK9 inhibitor evolocumab in patients with and without diabetes and the effect of evolocumab on glycaemia and risk of new-onset diabetes: a prespecified analysis of the FOURIER randomised controlled trial. Lancet Diab Endocrinol. 2017;5(12):941-50.

27. Deedwania P, Murphy SA, Scheen A, Badariene J, Pineda AL, Honarpour N, Keech AC, Sever PS, Pedersen TR, Sabatine MS, et al. Efficacy and Safety of PCSK9 Inhibition With Evolocumab in Reducing Cardiovascular Events in Patients With Metabolic Syndrome Receiving Statin Therapy: Secondary Analysis From the FOURIER Randomized Clinical Trial. JAMA Cardiol. 2021;6(2):139-47.

28. Oyama K, Furtado RHM, Fagundes A Jr, Zelniker TA, Tang M, Kuder J, Murphy SA, Hamer A, Wang H, Keech AC, et al. Effect of Evolocumab on Complex Coronary Disease Requiring Revascularization. J Am Coll Cardiol. 2021;77(3):259-67.

29. Lorenzatti AJ, Eliaschewitz FG, Chen Y, Fialkow J, Lu J, Baass A, Monsalvo ML, Hsu HC, Somaratne R, Ge J. Rationale and design of a randomized study to assess the efficacy and safety of evolocumab in patients with diabetes and dyslipidemia: The BERSON clinical trial. Clin Cardiol. 2018;41(9):1117-22.

30. Expert Panel on Detection, Evaluation, And Treatment of High Blood Cholesterol In Adults (Adult Treatment Panel III). Executive Summary of The Third Report of The National Cholesterol Education Program (NCEP) JAMA 2001, 285(19):2486-2497.

31. Kasichayanula S, Grover A, Emery MG, Gibbs MA, Somaratne R, Wasserman SM, Gibbs JP. Clinical Pharmacokinetics and Pharmacodynamics of Evolocumab, a PCSK9 Inhibitor. Clin Pharmacokinet. 2018;57(7):769-79.

32. Varbo A, Nordestgaard BG. Remnant lipoproteins. Curr Opin Lipidol. 2017;28(4):300-7.

33. Stroes E, Robinson JG, Raal FJ, Dufour R, Sullivan D, Kassahun H, Ma Y, Wasserman SM, Koren MJ. Consistent LDL-C response with evolocumab among patient subgroups in PROFICIO: A pooled analysis of 3146 patients from phase 3 studies. Clin Cardiol. 2018;41(10):1328-35.
34. Robinson JG, Nedergaard BS, Rogers WJ, Fialkow J, Neutel JM, Ramstad D, Somaratne R, Legg JC, Nelson P, Scott R, et al. Effect of evolocumab or ezetimibe added to moderate- or high-intensity statin therapy on LDL-C lowering in patients with hypercholesterolemia: the LAPLACE-2 randomized clinical trial. JAMA. 2014;311(18):1870-82.

35. Toth PP, Sattar N, Blom DJ, Martin SS, Jones SR, Monsalvo ML, Elliott M, Davis M, Somaratne R, Preiss D. Effect of evolocumab on lipoprotein particles. Am J Cardiol. 2018;121(3):308-14.

36. Hermans MP, Sacks FM, Ahn SA, Rousseau MF. Non-HDL-cholesterol as valid surrogate to apolipoprotein B100 measurement in diabetes: Discriminant Ratio and unbiased equivalence. Cardiovasc Diabetol. 2011;10:20.

37. Sniderman AD, St-Pierre AC, Cantin B, Dagenais GR, Després JP, Lamarche B. Concordance/discordance between plasma apolipoprotein B levels and the cholesterol indexes of atherosclerotic risk. Am J Cardiol. 2003;91(10):1173-7.

38. Tsimikas S, Gordts P, Nora C, Yeang C, Witztum JL. Statin therapy increases lipoprotein(a) levels. Eur Heart J. 2020;41(24):2275-84.

39. Balling M, Afzal S, Varbo A, Langsted A, Davey Smith G, Nordestgaard BG. VLDL Cholesterol Accounts for One-Half of the Risk of Myocardial Infarction Associated With apoB-Containing Lipoproteins. J Am Coll Cardiol. 2020;76(23):2725-35.

40. Varbo A, Benn M, Nordestgaard BG. Remnant cholesterol as a cause of ischemic heart disease: evidence, definition, measurement, atherogenicity, high risk patients, and present and future treatment. Pharmacol Ther. 2014;141(3):358-67.

41. Sharma A, Joshi PH, Rinehart S, Thakker KM, Lele A, Voros S. Baseline very low-density lipoprotein cholesterol is associated with the magnitude of triglyceride lowering on statins, fenofibric acid, or their combination in patients with mixed dyslipidemia. J Cardiovasc Transl Res. 2014;7(4):465-74.

42. Taskinen MR, Björnson E, Kahri J, Söderlund S, Matikainen N, Porthan K, Ainola M, Hakkarainen A, Lundbom N, Fermanelli V et al: Effects of Evolocumab on the Postprandial Kinetics of Apo (Apolipoprotein) B100and B48-Containing Lipoproteins in Subjects With Type 2 Diabetes. Arteriosclerosis, thrombosis, and vascular biology 2020:Atvbaha120315446.

43. Canuel M, Sun X, Asselin MC, Paramithiotis E, Prat A, Seidah NG. Proprotein convertase subtilisin/kexin type 9 (PCSK9) can mediate degradation of the low density lipoprotein receptor-related protein 1 (LRP-1). PLoS ONE. 2013;8(5):e64145.

44. Poirier S, Mayer G, Benjannet S, Bergeron E, Marcinkiewicz J, Nassoury N, Mayer H, Nimpf J, Prat A, Seidah NG. The proprotein convertase PCSK9 induces the degradation of low density lipoprotein receptor (LDLR) and its closest family members VLDLR and ApoER2. J Biol Chem. 2008;283(4):2363-72.

45. De Luca L, Arca M, Temporelli PL, Meessen J, Riccio C, Bonomo P, Colavita AR, Gabrielli D, Gulizia MM, Colivicchi F. Current lipid lowering treatment and attainment of LDL targets recommended by ESC/EAS guidelines in very high-risk patients with established atherosclerotic cardiovascular disease: Insights from the START registry. Int J Cardiol. 2020;316:229-35.

46. Ray KK, Molemans B, Schoonen WM, Giovas P, Bray S, Kiru G, Murphy J, Banach M, De Servi S, Gaita D et al: EU-Wide Cross-sectional observational study of lipid-modifying therapy use in secondary and primary care: the DA VINCI study. European Journal of Preventive Cardiology 2020.

\section{Publisher's Note}

Springer Nature remains neutral with regard to jurisdictional claims in published maps and institutional affiliations. 